\title{
"My Studying Stops When?": Addressing Delivery and Assessment of Lifelong Learning and Professionalism at the University of Regina
}

\author{
Doug Wagner \\ University of Regina \\ Esam Hussein \\ David DeMontigny \\ University of Regina \\ University of Regina \\ Douglas.Wagner@uregina.ca \\ Esam.Hussein@uregina.ca David.DeMontigny@uregina.ca
}

\begin{abstract}
Three one credit hour sequential courses are described as a tool for delivering and assessing learning outcomes in the CEAB mandated attributes of Life-Long Learning and Professionalism as an augmentation to existing work study programs at the University of Regina. The development of these courses through the Masters of Engineering program, allowing a smaller scale trial before full scale implementation at the undergraduate level is described. The future development and potential expansion of this course offering as a professional development offering to practicing engineers is also presented.
\end{abstract}

Keywords: Life-long learning, Professionalism, Graduate attributes, Continuous improvement

\section{INTRODUCTION}

The shift to Outcomes Based Assessment as the metric for Engineering education in Canada is an exciting change to the accreditation model for our University. One of the most challenging attributes to address and assess is 3.1.12 "Life-long learning" Co operative education work placement programs offer the institutions that employ them a valuable academic tool to address this attribute. Prior to the calendar year 2000-0 $1^{[1]}$ engineering programs at the $\mathrm{U}$ of $\mathrm{R}$ incorporated a mandatory cooperative education component. Changes in program demographics, and employment opportunities shifted the Cooperative Education programs to optional components at the University of Regina. While Life-long learning and professionalism are components of several undergraduate courses, tangible outcomes can be difficult to achieve solely through a traditional curriculum.

In 2013 a discussion document ${ }^{[2]}$ that proposed a parallel stream of sequential one credit hour courses targeted to address differentials between work study and non work study students within the faculty was presented to the Engineering Faculty. Directly implementing a new and incremental workload in the undergraduate program raised a number of concerns for implementation through faculty consultations.

An innovative solution was developed, allowing the Faculty to develop and implement models of these three courses in the Masters of Engineering (M. Eng.) program. This approach allows the Faculty to assess and improve this attribute strategy in a substantive way, and to plan for its implementation throughout the undergraduate program.

\section{Delivering and Assessing Life-long Learning}

To comply with the Canadian Engineering Accreditation Board's Graduate Attribute metrics the University of Regina, Faculty of Engineering and Applied Science has followed a commonly used strategy of curriculum mapping. For the majority of the assigned attributes, faculty teams have had little difficulty correlating course materials and class measures that can lead to an assessment-analysiscontinuous improvement model. Perhaps the most challenging attribute to fit to this model is the assessment and delivery of materials that promote life-long learning. No other attribute is so heavily reliant on inductive processes to assess its outcome. Course instructors can strive for inspiration for ongoing learning and development, students often with differentiating conventional lab and lecture tasks that have a short term feedback cycle with a concept that does not impact their enrichment until 
they are many years distant from formal educational settings.

Early in the mapping process, Faculty identified the Cooperative Work Study Programs offered at the University of Regina as tools that offered tangible content to instill the value of ongoing learning. Students having seen the application of educational content in the workplace see the practical value of their education, and importantly, are exposed to numerous permutations of engineering work that demonstrate the need for ongoing learning as a practicing engineer in Canada.

Happy that the Faculty has valid data from the Cooperative Work Study Program (both four year co op, and twelve to sixteen month internship), there also existed a problem: Prior to the year 2000, the work study programs were mandatory at the $U$ of $\mathrm{R}^{[1]}$. Changing student demographics, coupled with market challenges in the late 1990's led to the cooperative work study program becoming optional within the Faculty. Figure 1 shows the distribution of the spring 2015 graduates, based on their participation in the last work study program they would have been eligible to complete them.

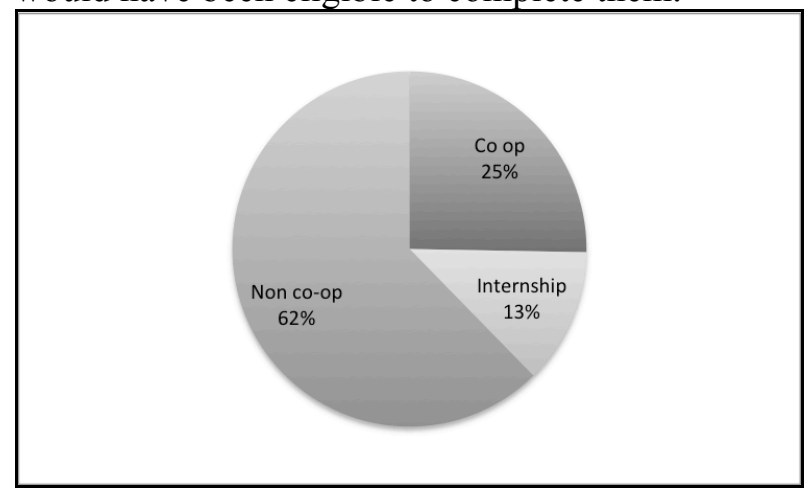

Figure 1: 2015 Student cohort work experience ${ }^{[3}$

With slightly more than a third of our students participating in work study programs the challenge was put to the Faculty to capture essential elements of the work-study programs in an innovative way.

Inspiration for this innovation came from Purdue University and their NUCL 29800/39800/49800 course offerings $^{[4]}$. Using the 29800 course syllabus as an example) stating in part "Career areas in nuclear engineering, job opportunities, areas of related study, topics of current interest, orientation, professional ethics, and responsibility., ${ }^{[5]}$, with detailed objectives and outcomes shown in Table 1.

Table 1: NUCL 29800 Objectives and outcomes $^{[5]}$

\begin{tabular}{l}
\hline $\begin{array}{l}\text { COURSE OBJECTIVES: } \\
\text { To inform the students about current trends and jobs in industry and government [10] } \\
\text { To describe the present impact, potential and issues of nuclear energy [8]. } \\
\text { To transmit an understanding of professional ethics and responsibility in nuclear engineering [6]. }\end{array}$ \\
\hline $\begin{array}{l}\text { COURSE OUTCOMES: } \\
\text { Students become aware of job opportunities in the field. } \\
\text { Students gain an understanding of nuclear energy contributions and issues. } \\
\text { Students gain an understanding of specific responsibilities of a nuclear engineering. }\end{array}$ \\
\hline $\begin{array}{l}\text { ASSESSMENT TOOLS: } \\
\text { Attendance is taken weekly. } \\
\text { The effectiveness of the course outcomes are assessed in Senior and Alumni surveys. }\end{array}$ \\
\hline
\end{tabular}

Using the Purdue model as a guide, the following sequential set of three one credit hour courses were outlined at the University of Regina ${ }^{[2]}$ shown in Table Two.

Table 2: U of R Life-Long learning Course Proposal ${ }^{[2]}$

\begin{tabular}{|c|c|c|}
\hline ENGG 501/551 & ENGG 502/552 & 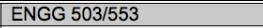 \\
\hline $\begin{array}{l}\text { Engineering Practice and } \\
\text { experience in Canada }\end{array}$ & $\begin{array}{l}\text { Engineering Practice and } \\
\text { continuing learning in the } \\
\text { workplace }\end{array}$ & $\begin{array}{l}\text { Engineering Practice, } \\
\text { Professional Development, } \\
\text { Communication and Ethical } \\
\text { Challenges }\end{array}$ \\
\hline $\begin{array}{l}\text { Course Material: } \\
\text { - } 3 \text { one hour presentations } \\
\text { from practicing engineers in } \\
\text { Saskatchewan and/or Western } \\
\text { Canada. Focus is on ongoing } \\
\text { and future tasks, application of } \\
\text { existing knowledge, } \\
\text { development from an } \\
\text { experienced engineer's } \\
\text { standpoint. Capture diverse } \\
\text { viewpoint if possible from } \\
\text { gov't/institutional, utility, and } \\
\text { entrepreneurial sectors. }\end{array}$ & $\begin{array}{l}\text { Course Material: } \\
\text { - } 3 \text { one hour presentations } \\
\text { on continuing } \\
\text { development in the } \\
\text { workplace. Presentation } \\
1 \text { - survey of structured } \\
\text { and non-structured } \\
\text { educational opportunities. } \\
\text { Presentation } 2-\text { APEGS } \\
\text { Continuing Professional } \\
\text { Excellence (CPE) } \\
\text { reporting structure and } \\
\text { examples of successful } \\
\text { strategies. } \\
\text { - Presentation } 3- \\
\text { "Selecting an ongoing } \\
\text { learning topic" }\end{array}$ & $\begin{array}{l}\text { Course Material: } \\
\text { - } 1 \text { to } 2 \text { one hour } \\
\text { presentation from working } \\
\text { engineers on } \\
\text { professional/ethical } \\
\text { situations as they have } \\
\text { experienced - capture } \\
\text { successful strategies for } \\
\text { dealing with these } \\
\text { experiences. } \\
1 \text { hour presentation on } \\
\text { potential case study (from } \\
\text { Professional practice } \\
\text { seminar if possible) }\end{array}$ \\
\hline
\end{tabular}

The course proposals sought to combine both life-long learning, and an enhanced awareness of professionalism into the course curriculum. External resources from the professional societies and industry were also designed into the course curriculum to further enhance the twin objectives of developing life-long learning and professionalism awareness in our graduates.

Various implementation strategies were considered, including weekday hourly delivery, and intensive weekend seminar or workshop strategies . The model incorporating this proposal incorporated both a one credit hour, and zero credit hour offering, allowing students participating in work study programs to also take the new 
courses as optional courses.. The graphical representation of course alternatives is shown in Figure 2.

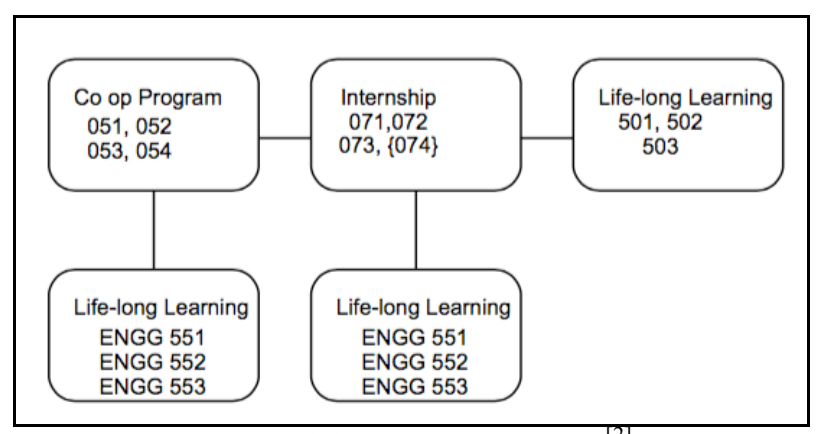

Figure 2: Initial Model of Course offering ${ }^{[2]}$

The new course model incorporate topics geared to develop an awareness of life long learning, and also awareness of the profession. The ENGG 50x courses would be mandatory for students not enrolled in Cooperative Education Work Study Programs, and the ENGG 55x course offerings are intended to allow students registered in the existing work study programs to take the ENGG 50x offerings as zero credit, hence zero cost electives should they wish.

Despite several creative solutions for implementation, a number of impediments stood in the way of direct implementation. These included:

- Concern over increased credit hour load in senior semesters

- Increased financial load on students

- Identification of instructional resources

- University Senate approval to structural changes

These challenges are not unique to any significant curriculum structural change, but as a new, untried initiative a method of testing the new program prior to full implementation was suggested from the faculty ranks.

\section{Pilot Program: Life-Long Learning and Professionalism}

Addressing the implementation concerns of the sequential one credit hour found a vehicle for implementation through the assessment of a similar course need in the Faculty's Masters of Engineering programs. The M. Eng. programs have a high subscription rate by international students. Through informal continuous improvement assessments within the Faculty, the benefits of including the undergraduate "Law and Professionalism" course as an M. Eng. requirement were identified and included in many of the programs. The Law and Professionalism course was assessed as beneficial, however it did not recognize many of the specific learning needs of international students who do not have the breadth that the undergraduate cohort has when taking this course in their final semester at the University of Regina.

A slight modification of the original ENGG 501-503 course objectives provided a solution to a number of problems:

- International Masters of Engineering students have a multi-semester course that can present professionalism concepts, and in that framework many of the life-long learning concepts can also be trialed to the benefit of the students.

- Enrollment increases in the existing undergraduate Law and Professionalism course were mitigated

- The new sequential course offering can be evaluated in terms of content, delivery and instructional load.

International students are not exposed to the regulations and traditions of practicing engineering in Canada as registered professional engineers.

The results, starting in the winter 2015 semester are three sequential one credit hour classes, ENGG 701, 702 and 703 which are piloting this outcome delivery concept. Figures 3, 4 and 5 summarize the course outlines for these three ENGG course offerings.

\section{ENGG 701 Engineering Practice and Experience in Canada}

Fundamentals of practicing engineering in Canada: Engineering is a profession: self-governance, registration and licensing, code of ethics.

Clear thinking: Mind Mapping.

Engineering is team work.

Engineer as a project manager.

Engineer and design.

Engineer and safety.

Engineering and sustainability and ecology.

Engineering and quality assurance

Figure 3: ENGG 701 Syllabus Winter 2015 


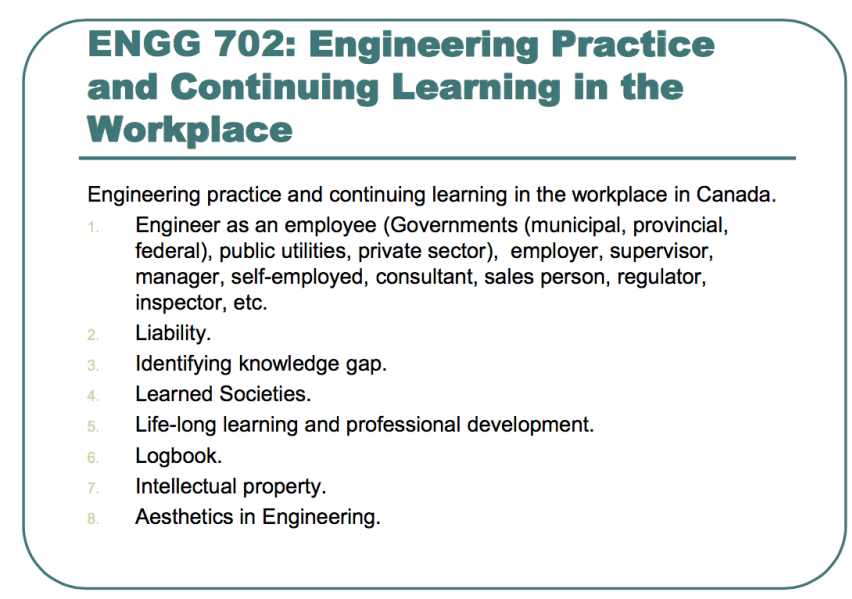

Figure 4:ENGG 702 Syllabus Spring 2015
ENGG 703 Engineering Practice, Professional Development, Communication and Ethical Challenges

Principles of engineering practice, professional development, communication and ethical challenges in Canada.

Professionalism.

Fairness and Equity.

Engineer is a communicator (non-verbal, verbal, and written): conduct, letters, memos, reports, presentations.

Crediting previous work.

Conflict of interest \& commitment.

Dealing with Conflict: people, demands of budget and time,

production quality and quantity

Ethical Challenges and whistle blowing

Figure 5: ENGG 703 Syllabus Fall 2015

The instructor assessment from the offering of ENGG 701 included the following assessments ${ }^{[6]}$ ( Hussein email: April 29-15)

- Comparative assessment of different codes of ethics for engineers and for other professions strengthened students' understanding of our own Provincial code of ethics.

- $\quad$ Students were quite eager to understand their own personal characteristics and those of others and appreciate that every personality trait has its role in a team.

- $\quad$ Students seemed to be surprised to learn that there is more to engineering practice than technical knowledge.

- Most surprising to me was the difference in individual perception of the same facts: each student had a different interpretation to the case you presented in class.

- $\quad$ Realizing the above, in next iteration I will get students to practice their skills in listening.

- What worked well was making attendance of a minimum 11 of 13 classes mandatory to pass the course, which emphasized at least symbolically professional behaviour. Inviting visiting speakers, I had a couple, was useful.

This first course was mostly aimed at raising awareness about professionalism, ethics and human behaviour.

\section{Assessment and Future Development}

Working with the initial assessment of ENGG 701, and the upcoming course delivery and assessment of ENGG 702 and 703, the Faculty will be in a position to refine and assess the merits of this strategy late 2015. Assuming a positive outcome at the graduate level, a refined model for ENGG 501, 502 and 503 can be presented and slated for implementation. Through this process a successful implementation outcome at the undergraduate level can be expected.

ENGG 702 includes the development of a ten year career development plan as part of the deliverables to further reinforce the concept of life-long learning.

The consultation process for the initial course proposals led to positive feedback from the Association of Professional Engineering and Geoscientists of Saskatchewan (APEGS). APEGS strongly supported practicing engineers assisting in the delivery of course material, to emphasize the importance of Life-Long Learning and Professionalism as ongoing metrics of interest to graduating engineers. APEGS also foresees the benefit of these courses being available as a professional development offering to working engineers in the province.

The development of this course proposal, and the move to develop initially at the graduate level also serves as an example within the Faculty of the CEAB continuous improvement process mapped in Figure 6: 


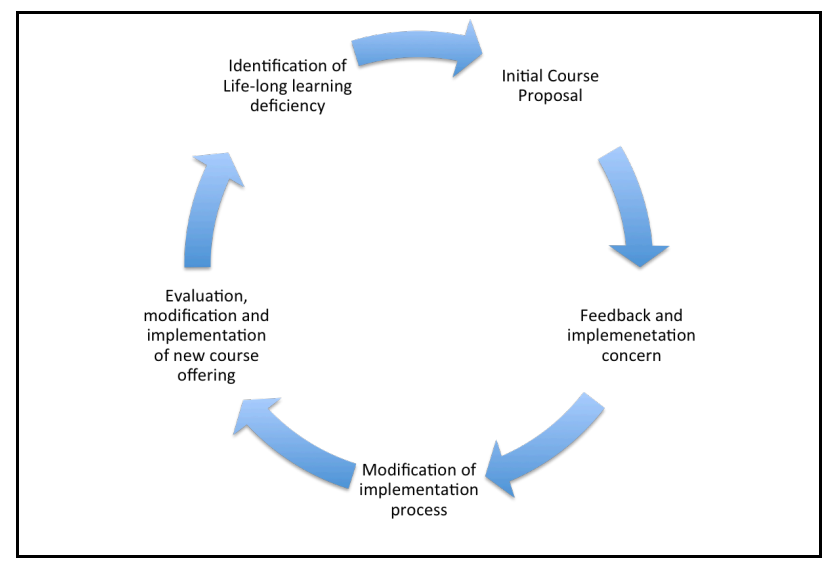

Figure 6: Continuous Improvement Map of Course Development

This model has been beneficial to the Faculty as a tool to evaluate one particular process of interest to all five program areas, and can serve as a template for other continuous improvement discussions arising from the move to Outcomes Based Assessment as an accreditation tool.

\section{References}

[1] Carlo Palazzo, U of R Co-op Coordinator, Career Center. Telephone Resource April 30, 2015

[2] Discussion Paper: Professionalism and Lifelong Learning Proposal August 1, 2013, Rev 1.2. Faculty Internal Documentation.

[3] Email correspondence: Paul Laforge, Director of Co-operative Work Study Programs, Faculty of Engineering U of R April 30, 2015.

[4]

https://engineering.purdue.edu/NE/Academics/Courses/N UCL29800 $39800 \quad 49800 /$ NUCL29800 3980049800 Accessed 01-08-2013

[5]

https://engineering.purdue.edu/NE/Academics/Courses/N UCL29800_39800_49800/NUCL29800_39800_ABETAccessed 01-08-2013

[6] Esam Hussein, Course evaluation ENGG 701 via email April 29, 2015. 